\title{
Д.Г. Самитов
}

\section{ПЕРВЫЕ РЕГИОНАЛЬНЫЕ ТЕАТРЫ США КАК АЛЬТЕРНАТИВА БРОДВЕЙСКОМУ КОММЕРЦИАЛИЗМУ}

\begin{abstract}
Противопоставив себя Бродвею и его коммерциализму, некоммерческие театры обратились к искусству, даже своим названием подчеркивая, что являются его альтернативой и строят свою деятельность совсем на других принципах. На Бродвее все отдавалось в жертву финансовому успеху. Рождение движения некоммерческих театров и стало такой альтернативой бродвейскому коммерциализму. Театр Марго Джонс, «Арена Стейдж», Кливленд Плейхаус, Театр Элли и многие другие стали художественными институтами, которые ставили во главу угла творческие задачи. Некоммерческие коллективы США сегодня являются важнейшей составной частью театрального прочесса в США.

Ключевые слова: продюсеры Бродвея, некоммерческий театр, Марго Джонс, Арена Стейдж, театр Элли, Кливленд Плейхаус.
\end{abstract}

Некоммерческие театры стали заметны для широкой публики после того, как в течение примерно десяти лет бродвейские постановки занимали главенствующую роль в американском театре. Противопоставив себя Бродвею и его коммерциализму, они обратились к искусству, даже своим названием подчеркивая, что являются его альтернативой и строят свою деятельность совсем на других принципах.

В конце Великой депрессии и в годы войны художественные и «малые» театры предшествовавших десятилетий практически прекратили свое существование. Единственными представителями театрального искусства в годы войны и после нее оставались бродвейские театры. Все они были коммерческими и представляли собой особую отрасль американской индустрии зрелищ.

Господство развлекательных жанров в театральном искусстве Америки было связано и с политической ситуацией в стране. Понятно, что в тяжелые годы войны развлечение, красивое зрелище требовались в больших масштабах, а в послевоенный период на развитие драматургии и театрального искусства США определенный отпечаток наложил резкий сдвиг вправо в общественно-политической жизни страны, названный в истории США эпохой маккартизма.

Американский театр, исходящий из кредо шоу-бизнеса, что искусство или мысль испугают и изгонят платящую публику, в это время обращается к развлекательности. Коммерческие театры показывали лишь то, что могло успокоить или отвлечь зрителя от жизненных реалий. На сценах преобладали мюзиклы, незамысловатые комедии, музыкальные шоу. Незначительность затрагиваемых проблем компенсировалась избыточностью оформления и качеством исполнения. Огромные залы, высокие цены на билеты, ориентация в репертуаре на мюзиклы и комедии с участием «звезд первой величины», роскошь декораций и костюмов - все это давало продюсерам Бродвея гарантию 
получения прибыли, но и соответственно предполагало осуществление значительных предварительных денежных вкладов. Стоимость постановок сильно возросла. Театр превратился в крупный бизнес.

Поэтому на Бродвее происходит перераспределение полномочий; продюсер становится не только главной, но единственной руководящей фигурой. До войны коммерческий продюсер также стоял во главе, но тогда большое значение имел и драматург. Теперь же продюсеры диктовали свою волю.

На Бродвее все отдавалось в жертву финансовому успеху. Это во многом изменило и взгляд на положение художника в обществе, который, по справедливому замечанию известного критика и театрального деятеля Р. Брустейна, «превратился попросту в один предмет купли-продажи». Главным недостатком американского театра после Второй мировой войны Р. Брустейн не без оснований назвал то, что «драма вступила в альянс с рынком» [1].

Характерная для послевоенной Америки атмосфера реакции не давала развития ни общественной мысли, ни культурной жизни страны. Авторитетный литературовед Ван Вик Брукс с горечью констатировал кризис в национальном искусстве этого периода. В книге «Писатель в Америке» он отмечал обесценивание гуманистических ценностей, призывал вспомнить лучшие традиции реалистической литературы 1920-1930-х гг. А театральный критик Э. Бентли, как бы вторя ему, констатировал в американском театре после Второй мировой войны почти «полное угасание художественной драмы в коммерческом театре... где театр выполняет роль предыстории для будущего возрождения...» [2. Р. 16]. Точно к такому же выводу приходит и Гарольд Клерман, режиссер и критик, руководитель лучшего в Америке 1930-х гг. театра «Груп»: «Я не хочу сказать, что театр умирает, театр всегда и везде кажется умирающим и никогда не бывает мертв. Наш тоже не умрет... но все указывает на то, что он ужасно болен» [3. Р. 7].

Таким образом, и современники, и исследователи связывают кризис искусства театра после Второй мировой войны с двумя обстоятельствами. Вопервых, с общественной и политической реакцией, а во-вторых, с абсолютным господством коммерции. И единственный возможный выход из подобного тяжелого положения сценического искусства многие видели только в борьбе с реакцией и коммерцией. «Наступил тот период, когда художник испытывает сильнейшее давление со стороны бизнеса... В таких условиях возможно только одно соотношение художника и бизнеса в театре - отношение антагонизма. Искусство и бизнес стали прямыми антагонистами» - так формулирует свое понимание ситуации Э. Бентли [2. Р. 6].

Пока бизнес торжествует - мечтой каждого бродвейского продюсера является постановка «смэша» - спектакля-хита, имеющего огромный успех и приносящего организаторам огромные доходы.

Для менеджера коммерческого театра в этой ситуации главным является независимо от подлинного качества спектакля и его художественной ценности добиться признания публики, что в конечном итоге обязательно выльется в ожидаемую прибыль. Поэтому компетентность продюсера в коммерческом театре определялась по его способности предвидеть пожелания, а вернее запросы потребительского зрительского рынка. Именно потребительский рынок определяет судьбу бродвейской постановки. Однако без профессиона- 
лизма Бродвея, всех его составляющих ни о каких дивидендах не может идти и речи.

Выбор пьесы - самая главная задача, стоящая перед продюсером. Расчет на кассовость спектакля, на максимально долгую его жизнь на сцене заставляет опираться на самого массового зрителя, на массовый средний вкус. Естественно, что постановки классических произведений, а также возобновление спектаклей, когда-то уже поставленных на сцене, становятся чрезвычайно редкими событиями, так как они не несут с собой того элемента занимательной неожиданности в сюжетном развитии, который столь важен для рядового зрителя. С другой стороны, глубокая философская проблема или авангардистские веяния тоже не приемлемы для бродвейских сцен, ибо могут адресоваться только узкому кругу более театрально изощренной публики. Таким образом, для постановок на коммерческой сцене наиболее типичны современная комедия и мюзикл, способные привлечь широкого зрителя. Это является условием для успеха и Бродвея, и лондонского Вест-Энда первого десятилетия уже XXI в.

Продюсеры коммерческих театров нанимают творческий состав исходя из стандартов, которые будут одобрены уже заранее изученным и апробированным средним зрительским вкусом, за исключением двух-трех известных исполнителей и «звезды». Бродвею в соответствии с его природой откровенно чужды волнение и забота о духовных и интеллектуальных потребностях артиста. Это никаким образом нельзя перевести в прибыль, а раз так, то гораздо проще заключить контракт с новым актером в строгом соответствии с его амплуа и не тратить время и тем более средства на творческое развитие и совершенствование артиста. Поэтому пока зрители продолжают довольствоваться коммерческой продукцией, многое из того, что относительно дешево, поверхностно, будет продолжать видеть свет огней бродвейских театров. Публика требует удовлетворения своих желаний, режиссер стремится отвечать требованиям публики, критики же Нью-Йорка пытаются объяснить эту ситуацию. Газета «Нью-Йорк Таймс» и другие ежедневные газеты регулярно на утро после каждой премьеры печатают рецензии на новый спектакль. В отличие от европейских стран, да, пожалуй, и большинства других городов США, где мнение театрального обозревателя расценивается как частный взгляд на художественный процесс или отдельное его проявление, отзыв критика нью-йоркской ежедневной газеты - это вердикт судьи и нередко беспощадный приговор или откровенная реклама.

Среди признанных продюсерами Бродвея в послевоенные годы, пожалуй, единственным исключением был театр «Гилд». Эта театральная организация, существовавшая с 1918 г., выросла из «малого» театра «Вашингтон Сквер Плейерз». Правда, к этому времени «Гилд» почти утерял свои прежние прогрессивные и художественные идеалы и превратился в обычную бродвейскую продюсерскую компанию, опиравшуюся в своей деятельности на популярность «звезд» и развлекательность.

Но время от времени «Гилд» все-таки вспоминал о своем славном прошлом и брал на себя смелость поставить что-нибудь художественное или экспериментальное. Иногда это оправдывалось и творчески, и финансово, как в случае постановки в 1943 г. мюзикла «Оклахома» П. Роджерса и О. Хаммерстейна. Он стал величайшим «смэшем», открывшим новые воз- 
можности музыкального спектакля-шоу, принесшим театру славу и миллионные доходы. Чаше же подлинное творчество денег не приносило, но способствовало сохранению художественного имиджа «Гилда», как в случае постановки пьесы «Продавец льда грядет» Ю. О'Нила в 1946 г. Но со временем смелость «Гилда» все убывала.

Отмечая бесспорный финансовый практицизм Бродвея, нельзя не сказать о его высоком профессионализме в период создания и проката постановки в целом. Менеджмент в коммерческом театре отточен до совершенства - в противном случае это может привести к закрытию предприятия. Получить высокие дивиденды можно лишь при высоком профессионализме всех составляющих элементов постановки, начиная с весьма значительных предварительных финансовых вложений в творческие и постановочные ресурсы будущего спектакля. Не случайно, благодаря этому многие бродвейские «хиты» получили не только национальную, но и мировую известность. Среди них «Кабаре», «Отверженные», «Кошки», «42 улица», «Мисс Сайгон», «Призрак оперы», «Чикаго», «Продюсеры» и др.

Хотя социальные и экономические механизмы, которые в свое время создали Бродвей, работают по-прежнему, но в послевоенный период он во многом изменился. По мере того как в течение лет росла стоимость постановок, Бродвей медленно видоизменялся, ориентируясь на более денежную публику, а Голливуд, радио и телевидение захватили массовые развлечения. Если в начале XX в. Бродвей был намного значительнее Голливуда, то в последующие годы он постепенно уступил свои позиции и после Второй мировой войны стал весьма зависим и от Голливуда, и от телевидения, потому как только продав свой спектакль в кино или на ТВ, бродвейский продюсер может рассчитывать на высокие дивиденды - главную цель своей деятельности. Хотя все зависит от уровня постановки - даже в начале XXI столетия на примере фильмов «Призрак оперы» и «Продюсеры» можно констатировать, что мировая киноиндустрия не пропустила достижения коммерческой сцены.

Однако именно кризис американского послевоенного театра явился одновременно и началом его нового развития. В нем начинают консолидироваться силы, противостоящие коммерческой сцене. Произошло так, что монопольное господство коммерческого театра породило его альтернативу офф-Бродвей. Желание театральных деятелей реализовать свои творческие силы в художественном театре привело многих из них к идее создания собственных коллективов в противовес бродвейскому театру.

К середине столетия, как отмечают современники, узость бродвейских постановок стала настолько очевидна, что целое поколение драматургов, актеров, режиссеров вынуждены были заранее отказаться от этих театров. Альтернативой развлекательно-театральной индустрии становились коллективы, развивающие традиции национальной драматургии, режиссуры, актерского творчества, открывающие новые горизонты в сценическом искусстве. Показательно, что подобная ситуация характерна и для других видов искусств США. Так, «изучение истории американской литературы, - пишет исследователь Б.А. Гиленсон, - позволяет обнаружить интересную закономерность: время от времени, в какие-то наиболее драматические моменты национальной истории, в периоды обострения социальной борьбы выходили книги, по- 
требность в которых настойчиво ощущалась и которые словно бы аккумулировали в себе смутное недовольство и жажду перемен» [4. С. 40].

Рождение движения некоммерческих театров и стало такой альтернативой бродвейскому коммерциализму, притягивавшей все новые здоровые и творческие силы американского театра.

После войны появилось новое поколение, желающее работать в театре. Но для молодых актеров, режиссеров найти работу по специальности шансов практически не было. За пределами Нью-Йорка спрос на драматических исполнителей отсутствовал, так как региональные театры к концу 40-х гг. в Америке практически не существовали. Когда молодые, творчески одаренные люди не находили работу на Бродвее, им необходимо было найти место, где они могли бы попробовать силы, дать приложение своей творческой энергии. И молодые художники, будучи не в силах изменить мир большого бизнеса Америки, отделились от него, стремясь подчеркнуть свою независимость и отличность во всем: и в занятиях любимым театральным делом, и в репертуаре, и в актерском творчестве. Они стали создавать свои коллективы, театры, студии, труппы, группы. Так началось движение некоммерческих театров.

Родоначальником движения региональных театров в США после Второй мировой войны стала Марго Джонс. В 1947 г. она создала в Далласе небольшой профессиональный театр. Каждый год в нем ставилось шесть новых постановок. Репертуар включал в себя как классические произведения, так и новую драму. На спектакли Шекспира, Ибсена, Чехова больше всего продавалось билетов. Просветительским задачам коллектива способствовали специальные курсы занятий для молодежи. М. Джонс последовательно строила свой новый театр на принципах предшествующих поколений. Подтверждая эти мысли, М. Джонс ссылалась на опыт деятелей 1910-1930-х гг.: «Мы должны поблагодарить людей, чей идеализм помог создать движение двадцатых годов - «Провинстаун», Театр Гилд, О’Нила. Поблагодарить и тех, кто пришел позже: за «Груп», Федеральный проект, коммьюнити театры, региональные театры, театры в колледжах и за постоянную инфильтрацию новой крови в профессиональные театры Бродвея» [5. Р. 10].

«Кливленд Плейхаус» занимает важное место в развитии движения региональных театров США. Он оказал решающее влияние на жизнь миллионного Кливленда и всего штата Огайо. В 1962 г. по инициативе жителей в пригороде Кливленда был учрежден и открыт Шекспировский фестиваль Великих озер, предназначенный для показа классических произведений. Летний театр с залом на 989 мест до настоящего времени знакомит зрителей с классическими произведениями.

Американские исследователи считают, что период зарождения движения региональных профессиональных театров приходится на начало 1960-х гг. Знаменитый театр «Аренда Стейдж» стал предшественником этого явления и, в свою очередь, развивал идеи малых и художественных театров. Руководители театра во главе с 3. Фичендлер, обратившись за поддержкой к Фонду Форда, смогли построить собственное здание, которое было открыто в 1961 г. В «Арене Стейдж» никогда не появлялись откровенно коммерческие поделки, в театре ставились классика и современные пьесы: Б. Шоу, А. Чехова, Ю. О’Нила, Т. Уайлдера, Ж. Ануя, Э. Ионеско, Г. Питера. С успехом основательница театра работала в нем до конца сезона 1990/91 года, т.е. пятьдесят 
лет, проводя политику художественных ценностей, строгого отбора репертуара и сохранения ядра труппы.

Театр «Элли» (Alley Theatre) в г. Хьюстон был основан в 1947 г., на три года раньше, чем «Арена Стейдж» в Вашингтоне. Но возник он как объединение любителей сценического искусства. Основательница театра Нина Вэнс начинала свою сценическую деятельность еще у Марго Джонс. Н. Вэнс так определяла деятельность руководимого ею коллектива: «Я полагаю, мы были логическим продолжением движения „малых“ театров, мы были антрепризой по принципу „сделай сам“» [6. Р. 27]. С самого начала Нина Вэнс и ее единомышленники выдвинули программу, в которой ратовали за искусство высоких художественных достоинств и демократического содержания. В 1954 г. «Элли» стал профессиональным театром. Он постоянно проводил подписку на абонементы и жил лишь на доходы от кассы. Помог Фонд Форда, который в 1960 г. дал театру дотацию в 156 тыс. долларов для того, чтобы в течение трех сезонов можно было приглашать из Нью-Йорка лучших актеров и доплачивать им по 200 долларов в неделю. Также с помощью жертвователей было построено здание, которое было открыто в 1968 г. Театр имел два зрительных зала с разными сценическими площадками. Большой зал на 798 мест был построен в форме веера и малый зал на 300 мест предназначался для экспериментальных работ. В репертуаре были классические, современные и особенно русские авторы.

Н. Вэнс проработала в своем театре до конца жизни. Ей не раз предлагали перейти на Бродвей, что часто являлось мечтой любого театрального деятеля. Но, подобно Марго Джонс, она всегда оставалась верной своим корням: своему театру и своему Техасу. После смерти Н. Вэнс в 1980 г. руководителем театра «Элли» стал Пэт Браун, который успешно продолжил линию своей предшественницы. Самым главным из того, что ему удалось сделать, следует считать возрождение постоянной труппы. Не останавливаясь на достигнутом, Пэт Браун в последующие годы также тщательно отбирал необходимых для слаженной художественной деятельности театра постоянных художников, режиссеров, других творческих специалистов. Он даже стал приглашать драматургов на сезон, считая, что актеры тоже будут участвовать в процессе создания пьес, а это, в свою очередь, будет способствовать улучшению творческой атмосферы всего коллектива.

Конечно, новое время требовало порой художественных компромиссов региональных театров. Увеличение их бюджетов, большие театральные комплексы из нескольких залов, зависимость от попечительских советов, увеличивающееся число абонементодержателей, выполнение контрактов с профсоюзами приводило их к прагматичным заботам и заботам об экономической стороне их деятельности. Крупнейшие и старейшие некоммерческие драматические коллективы США, существующие сегодня, осознают, что театр - это прежде всего творческий, художественный институт и ценить его надо именно за его вклад и влияние на духовную жизнь тех людей, для которых он работает.

\section{Лuтература}

1. Brustein R. Muddy Track at Lincoln Center // The New Republic. 1964. December 26. P. 26-27.

2. Bentley E. The Playwright as Thinker: A Study of Drama in Modern Times. New York: Harvest Books, 1987. 416 p.

3. Clurman H. Lies Like Truth. Theatre Reviews and Essays. New York, 1958. 300 p. 
4. Гиленсон Б.А. Социалистическая традиция в литературе США. М. : Наука, 1975. 200 с.

5. Jones M. Theatre 50: A Dream Come True - Ten Talents in the American Theatre, Norman, University of Oklahoma Press, 1957. 299 p.

6. Zeigler J.W. Regional Theater: The Revolutionary Stage, MN, University of Minneapolis Press, $1973.277 \mathrm{p}$.

Dmitry G. Samitov, Russian Institute of Theatre Arts - GITIS (Moscow, Russian Federation). E-mail: goodluck@bk.ru

Vestnik Tomskogo gosudarstvennogo universiteta. Kul'turologiya i iskusstvovedeniye - Tomsk State University Journal of Cultural Studies and Art History, 2020, 40, pp. 190-196.

DOI: $10.17223 / 2220836 / 40 / 16$

THE FIRST REGIONAL THEATRES OF THE UNITED STATES AS AN ALTERNATIVE TO BROADWAY COMMERCIALISM

Keywords: Broadway producers; nonprofit theatre; Margo Jones, Arena Stage; Alley Theatre; Cleveland Playhouse.

The article aims to draw attention to the problem of the emergence and development of creative troupes of a new type. Non-profit theatres became noticeable to the public after a ten-year dominance of Broadway productions played on stages of American the ater. Contrary to Broadway and its commercialism non-profit theatres turned to art, becoming its alternative.

The venues mostly performed musicals, uncomplicated comedies, musical shows. Huge halls, high ticket prices led to the fact that the theatre turned to a major business. The desire of theatrical figures to realize their creative powers in the art theatre led many of them to the idea of creating their own companies in opposition to the Broadway theatre in many regions of the United States.

It was the nascence of the movement of non-profit theatres that became an alternate to Broadway commercialism, attracted all the new creative forces of the American theatre.

Analyzing the activities of number of non-profit theatres such as Cleveland Playhouse, Arena Stage, Alley Theater, the conclusion was made that they all played an important role in the development of the movement of the regional theatres of the United States.

The famous "Arena Stage" Theatre, like other regional theaters, developed traditions of nonprofit theatres of the USA, including the ideas of "little" and "arti" theatres.

The study of non-commercial drama theatres in the United States is relevant for modern Russia. Exploring the process of evolution of noncommercial companies the author concluded that the theatre is primarily a creative, artistic institution, that is to be valued precisely for its contribution and influence on the spiritual life of the audience.

\section{References}

1. Brustein, R. (1964) Muddy Track at Lincoln Center. The New Republic. 26th December. pp. $26-27$.

2. Bentley, E. (1987) The Playwright as Thinker: A Study of Drama in Modern Times. New York: Harvest Books.

3. Clurman, H. (1958) Lies Like Truth. Theatre Reviews and Essays. New York: [s.n.].

4. Gilenson, B.A. (1975) Sotsialisticheskaya traditsiya v literature SShA [The Socialist Tradition in US Literature]. Moscow: Nauka.

5. Jones, M. (1957) Theatre 50: A Dream Come True - Ten Talents in the American Theatre. Norman: University of Oklahoma Press.

6. Zeigler, J.W. (1973) Regional Theater: The Revolutionary Stage. MN, University of Minneapolis Press. 